\title{
LEVINAS, RICOEUR E OS IMPREVISTOS DA HISTÓRIA
}

\author{
LEVINAS, RICOEUR AND THE HISTORY'S UNEXPECTED
}

\author{
MARCELO FABRI ${ }^{1}$ \\ (UFSM / Brasil)
}

\begin{abstract}
RESUMO
O artigo discute o problema da condição histórica em Levinas e Ricoeur tomando como fio condutor a relação entre ética e ontologia, bem como o papel da memória em história e em filosofia. O ponto de partida é a questão de Jan Patocka, em um livro intitulado Ensaios Heréticos: “A história tem um sentido?”. Diante da crise do sentido que caracteriza o mundo contemporâneo, procura-se mostrar que o não-sentido é uma possibilidade sempre iminente nas situações históricas, mas, para que isso não seja a última palavra na interpretação de nossa humana condição, vale enfrentar a seguinte tarefa: retomar um confronto dialógico entre a crítica ética da ontologia (Levinas) e o desejo de ser, essencial em toda busca de sentido ou esforço hermenêutico (Ricoeur).
\end{abstract}

Palavras-chave: Sentido. Não-sentido. Condição histórica. Ética. Fenomenologia.

\begin{abstract}
The paper examines the problem of the historical condition in Levinas and Ricoeur. The main issue is the relation between ethics and ontology, as well the role of memory in history and philosophy. The starting point is Patocka's question in his book heretical essays: "does History have a meaning?" To answer this question we try to show that, in fact, the historical condition supposes a real possibility of non-meaning in every historical situation. Even so the search of meaning is a kind of philosophical task that implies a dialogue between the ethical critique to ontology (Levinas) and the desire of being (Ricoeur), essential in each search of meaning or hermeneutical work.
\end{abstract}

Keywords: Meaning. Non-meaning. Historical condition. Ethics. Phenomenology.

Levinas e Ricoeur: dois filósofos tocados pelos imprevistos da história. Ambos viveram e testemunharam, ao longo de suas vidas e obras, a crise do sentido que, sob muitos aspectos, configurou o século XX. Com o presente trabalho pretendemos abordar a referida crise a partir da interpretação que os dois pensadores fazem da assim chamada condição histórica. Se Levinas critica a totalidade e o ser como guerra, apontando para a absorção do sujeito na inteligibilidade anônima do logos, Ricoeur, por sua vez, é o hermeneuta que esteve sempre às voltas com o desafio do sentido, esforçando-se para dar ao discurso ontológico um teor de humanidade que Levinas só teria admitido sob a condição de que não a ontologia, mas sim a ética fosse considerada a filosofia primeira. No que diz respeito ao problema da história, esta diferença terá repercussões importantes. Se em Levinas o existente humano, no discurso historiográfico, se vê às voltas com sua possível dissolução, uma vez que é a totalidade que confere o sentido último, já 
Ricoeur se preocupou em defender, mediante um diálogo entre o filósofo e o historiador, a possibilidade de se dar voz àqueles que, estando para sempre inscritos no passado, perderam toda a chance de falar no presente. Seria o caso, então, de apresentar dois discursos diferentes, destacando apenas a discordância entre dois gigantes da ética contemporânea?

Levinas e Ricoeur foram discípulos de Husserl, e este fato os torna preocupados com o sujeito humano concreto, sensível, respondente. Nas próprias críticas que dirigem ao pai da fenomenologia, ambos sempre retomam a figura de um eu respondente que não apenas experimenta os acontecimentos, mas também os interroga tendo em vista o imprevisível que eles contêm. Na nossa perspectiva, Levinas e Ricoeur constroem sua argumentação sobre a condição histórica, numa espécie de retomada crítica da fenomenologia. Mas eles o fazem a partir da crise do sentido que parece ter comprometido o projeto transcendental da obra de Husserl. Que crise é esta? Qual o seu impacto sobre a interpretação de nossa historicidade? Ao enfrentarem a crise, Levinas e Ricoeur trilham caminhos diferentes, muitas vezes conflitantes, mas, ao final das contas, inegavelmente complementares.

\section{Entre sentido e não sentido: o destino da Europa}

Comecemos com a pergunta: que se entende, aqui, por sentido? Um dos textos que marcaram o pensamento de Ricoeur sobre a história é o livro Ensaios Heréticos, de Jan Patocka. Nesta obra pungente sobre o destino da Europa, o filósofo de Praga pôs em questão a afirmação de que o conceito de sentido é evidente por si mesmo. Sentido, pensa ele, não é o mesmo que significado. Se o significado implica uma referência objetiva ligada à esfera do logos (Frege e Husserl, por exemplo), o sentido diz respeito à nossa maneira de conceber. É assim que perguntamos se a vida e o sofrimento têm um sentido, mas não um significado. Ora, se Husserl via na categoria de significação a chave para compreender o mundo humano e, consequentemente, a história, Patocka se aproxima de Heidegger para dizer que o sentido é aquilo sobre cujo fundamento algo se torna compreensível (Cf. PATOCKA, 1999, p. 94).

A partir de Heidegger, Patocka mostra que o sentido (Sinn) tem um caráter fundador, pois é ele que torna alguma coisa compreensível. Mas, para chegarmos ao sentido, não basta dirigir-se à intencionalidade, isto é, à consciência em seu dinamismo doador originário. $\mathrm{O}$ caminho em direção ao sentido implica desvelar algo que não estava à vista (Cf. PATOCKA, 1999, p. 95). De 
que se trata? Em Husserl é fundamental compreender o mundo do espírito em termos de motivação. As vivências intencionais possuem uma ligação que não é causal ou natural, mas motivacional. Um exemplo: ponho uma conclusão a partir das premissas. Ou ainda: ponho um valor a partir de valorações. Eis por que em Husserl é fundamental reconhecer que toda afecção de um ego implica, em contrapartida, a reação ativa pela qual um ato terá um fim e o eu, por sua vez, liberdade (Cf. HUSSERL, 1982, III, § 55, p. 302). Na perspectiva de Patocka, é justamente esta relação entre sentido e finalidade que pode ser posta em questão. Nem sempre um sentido serve a um fim! O sentido não se explica em termos de finalidade. Por quê? Porque "uma ação bem pode servir a um fim ou ser útil e, no entanto, perder seu sentido" (PATOCKA, 1999, p. 95). A ciência moderna, que tornou a sociedade rica em meios, não oferece recursos para se colocar ou abordar o problema do sentido. No plano individual, o sintoma neurótico tem sentido, embora não possua finalidade. $\mathrm{O}$ mesmo vale para nossos erros, que embora não tenham finalidade, nem por isso deixam de ter um sentido.

A fenomenologia husserliana refletiu abundantemente sobre o caráter posicional ou dóxico da consciência (Cf. HUSSERL, 2006, §§ 103-106). Nossos valores, por exemplo, resultam de múltiplos atos de valoração, formando a base indispensável a um agir racionalmente motivado. O querer autêntico, para Husserl, é aquele que busca realizar um bem intencionado sob a forma de um fazer (Fiat) criador (Cf. HUSSERL, 2009, § 16). Do ponto de vista formal (e não metafísico), o bem, o belo e o verdadeiro são valores inseparáveis. Patocka, por sua vez, insiste em que a realização dos valores pode se tornar um fim, mas os valores não são fins em si mesmos. Próximo, aqui, de Heidegger, o filósofo tcheco afirma que os valores apenas mostram que as coisas têm sentido para nós, e que não estamos no mundo como espectadores indiferentes. Dito de outro modo, o sentido não depende unicamente de uma doação intencional. Como assim? É que, para Patocka, são os entes que nos interpelam, são os valores que nos acenam. O bem não é um fim posto pela consciência, mas uma possibilidade de abertura, de esquecimento de si mesmo. Benevolência e graça são bens que o mundo admite, mas não há garantia do sentido contra o não-sentido. A perda de sentido é um fenômeno da experiência concreta. No mundo contemporâneo, afirma Patocka, "todo o sentido pode estar perdido ou perder-se” (1999, p. 98).

O "sentido" das coisas nos pertence? Alguém detém o sentido das coisas? Ora, Patocka tem em mente o conceito heideggeriano de compreensão, isto é, ele entende o compreender a partir de nosso estar aí, como algo que se dá no interior de nossa existência (Cf. HEIDEGGER, ethic@-Florianópolis, v. 11, n. 1, p.125-139. Jun. 2012. 
2002, § 31). É correto afirmar que somos nós que damos sentido às coisas, mas o sentido não é criado por nós, vale dizer, não somos os árbitros da doação de sentido, exatamente porque a esfera do sentido é problemática. Além do conceito de compreensão vindo de Heidegger, Patocka tem a marca do niilismo de Nietzsche. Com o niilismo, experimenta-se a consciência do possível não-sentido de tudo. A crença ingênua no sentido é constantemente atormentada pelo fantasma do niilismo. Lembremos que Patocka morreu em meio a experiências dolorosas, relacionadas a um interrogatório policial. Ele viveu a perda de sentido em sua própria carne. Em termos filosóficos, isso significa: o sentido é o resultado parcial de uma relação ao sensato, mas esta relação não nos protege do abalo contínuo da consciência que ainda acredita na posse do sentido ou confia na razão (Cf. PATOCKA, 1999, p. 104).

Apresentemos a questão de maneira histórica. Segundo Patocka, o mundo pré-moderno é aquele em que o sentido está dado, cabendo ao ser humano integrar-se à ordem estabelecida. Exemplos dessa integração foram vistos: na metafísica, com a idéia de um mundo verdadeiro; na Roma antiga, com a idéia de um Estado verdadeiro; na Idade Média, com o desafio de conciliar razão e fé. No mundo moderno, o sentido dado já não existe. A natureza torna-se objeto de construções matemáticas, e isso provoca uma dissolução da intuição concreta (Cf. HUSSERL, 1976; Cf. PATOCKA, 1999, p. 117). Na era planetária, eis que a Europa se descobre em pleno não-sentido. Ela deixa de ser o centro da história, e o homem, por sua vez, torna-se organismo biológico fazendo parte do mundo material. O ser humano não é aquele que vive corporalmente ou de modo encarnado, mas aquele que é visto por uma atividade teórica vazia de sentido, isto é, pelo olhar objetivo das ciências naturais (Cf. PATOCKA, 1999, p. 122). Se o ser humano não pode viver com a certeza do não-sentido, também é verdade que ele pode viver no contexto de um sentido buscado e problemático (Ibid., p. 124). Afinal, viver, depois do advento da filosofia há mais de dois mil anos, é viver na esfera da problematicidade. Em seu Prefácio aos Ensaios Heréticos, Ricoeur escreveu:

A perda do "sentido" não é a queda no "não-sentido", mas o acesso à qualidade do sentido implicada na própria busca. Jan Patocka reencontra, assim, o tema socrático do "cuidado da alma" e da "vida examinada" (RICOEUR, 1999, p. 16).

Essa coragem de viver na esfera da problematicidade, sem acanhamento nem dogmatismo, exige uma conversão (metanoia) filosófica capaz de abrir-se ao problema da responsabilidade histórica e política. Em sua leitura aguda de Patocka, Ricoeur mostra que o 
desafio recai não sobre o indivíduo isolado, mas sobre a Europa ou humanidade européia como um todo. Assumir a responsabilidade pelo não-sentido implica um desenraizamento, uma abnegação, um responder que enfrentam o niilismo. As duas guerras mundiais são como que a evidência terrível das potências da Noite. Pensando o desfecho trágico da Europa no século XX, Patocka afirma:

\begin{abstract}
A guerra como "tudo é permitido" universal, como liberdade selvagem, invade os Estados, torna-se "total" (...). A guerra representa, ao mesmo tempo, o grande empreendimento da civilização industrial, o produto e o instrumento de uma mobilização total (como bem viu Ernst Jünger), e a liberação das potencialidades orgiásticas que em nenhum outro lugar podem permitir-se de conduzir a embriaguez da destruição até esta extremidade última (...). Que o demoníaco (la démonie) possa atingir seu ponto culminante precisamente num período de lucidez e de racionalidade maximais, é, todavia, um fenômeno sem precedentes. (PATOCKA, 1999, p. 180-181).
\end{abstract}

$\mathrm{Na}$ situação extrema há ainda algum ponto em que se apoiar? Patocka fala em solidariedade entre os arruinados. A experiência do front compreende-se como experiência limite que poderia gerar uma libertação, ou uma saída do estado de guerra total. Ricoeur, por sua vez, se pergunta: por que esta experiência não encontrou aplicação nos conflitos do século XX e por que ela não encontrou seu potencial de salvação? (Cf. RICOEUR, 1999, p. 19). Para além do duplo dogmatismo (o do "sentido" e o do "não-sentido"), há a resistência possível entendida como solidariedade entre os vitimados. Este pensamento prolonga, segundo Ricoeur, o antigo tema socrático do cuidado da alma ou vida examinada. Para Patocka, ele é o motivo condutor da Europa, motivo este que, na perspectiva de Ricoeur, se traduz, hoje, na pergunta: "Este socratismo político tem sua chance"? (Ibid.). De nossa parte, pensamos que a reflexão ricoeuriana sobre os imprevistos da história é uma resposta a esta questão. No caso de Levinas, o problema é mais delicado, pois, antes de qualquer decisão sobre o destino da Europa, é preciso refletir sobre a insuficiência de seu ideal de liberdade para proteger-nos das potências da Noite.

\title{
2. Condição histórica e dissolução do sentido
}

É precisamente a iminência histórica das potências da noite que presidiu à reflexão filosófica de Levinas ao longo de toda a sua obra. Seu ponto de partida é uma fenomenologia do Elemental. Entendido como meio (milieu), o Elemental faz que as coisas venham até nós. Elemento é o meio impessoal ou terreno comum que a ninguém é dado possuir: é a terra, o mar, a luz, etc. Com efeito, é pelo não-possuível que algo se torna apto a oferecer-se à posse. "O 
navegador que utiliza o mar e o vento domina esses elementos, mas nem por isso os transforma em coisas" (LEVINAS, 1978, p. 104). É nesse sentido que o elemento simboliza o retorno à desordem total. Na medida em que não se encontra a serviço de nenhum pensamento, ele é sinônimo de força incontrolável ou abismo abrindo-se de modo imprevisível em várias épocas. $\mathrm{O}$ elemento não possui rosto. Não podemos abordá-lo, uma vez que ele sempre nos envolve. Qual a relação que esse incontrolável mantém com a noite?

$\mathrm{Na}$ fenomenologia de Levinas, noite simboliza a suspensão da justiça. As relações interhumanas supõem a luz do dia, requerem a claridade diurna. "A noite é o perigo mesmo de uma justiça suspensa entre os humanos" (Cf. LEVINAS, 1977, p. 168). Ligada ao conceito de Elemental, a noite simboliza os momentos históricos em que as fronteiras deixam de existir. Do mesmo modo que os fenômenos da natureza desencadeiam forças incontroláveis, há, na própria história, os instantes em que a ordem se desfaz. Onde, um "estar em casa"? O retiro em si mesmo, a interioridade em que poderíamos nos refugiar é possível? Esta pergunta é decisiva para Levinas. Se a diferença entre dia e noite, entre exterior e interior se esvai, o odor dos "campos" já se fez presente. Assim:

\footnotetext{
A violência não é mais um fenômeno político da guerra e da paz, sempre além da moral. É o abismo de Auschwitz ou o mundo em guerra. Mundo que perdeu sua "própria mundanidade". É o século XX (LEVINAS, 1977, p. 170).
}

Diante dessa invasão da noite em pleno dia, vale dizer, do desencadear de forças elementais no interior da civilização, somente a entrada em si mesmo poderia representar um fato singular e único. Situação chamada por Levinas de situação do Estado de Israel, entendendo-se por isso não uma comunidade política ou particularidade cultural, nem mesmo a experiência religiosa de um povo, mas, sim, uma categoria filosófica que traduz algo comum aos seres humanos. Como assim? É que o "sem saída", representado pela experiência da noite, é, curiosamente, a condição para uma "entrada em si mesmo". Interioridade sob a forma de temor e de refúgio, ou ainda, de despertar para o humano. O que entender por humano? Não mais que o “não-lugar" ou "sem-lugar" a partir do qual se responde pelo outro. Nesse sentido, pode-se dizer que o humano é o fenômeno da ruptura do ser e da perseverança no Ser (Cf. LEVINAS, 1977, p. 167).

Vejamos a questão pela perspectiva do dia. A vontade livre, que é o emblema da história do Ocidente, permite pensar o existente humano como capaz de ação. Esta se renova 
infinitamente. A liberdade nos colocaria acima da própria história. A história é limitação, é condicionamento. Por quê? Porque nosso existir é tempo, e este, por sua vez, é condição do irreparável. Aquilo que foi consumado chama-se fato. O presente que carrega o que foi realizado nos escapa, não podemos dominá-lo. Tudo o que foi consumado como fato pesa sobre nós como um destino (Cf. LEVINAS, 1997, p. 9). É a partir deste irreparável ou inapagável que a condição história é pensada. A liberdade existe? Para Levinas, o Ocidente se reconhece, justamente, em seu movimento de desprendimento em relação a uma prisão, ou como luta para escapar a um destino irreversível. Trata-se de um poder de renovação diante das vicissitudes da história, um poder de separação, uma forma de existência capaz de assumir, na própria história, a condição de livre em relação àquilo que passou ou foi, ou ainda, em relação àquilo que nos prende, enraíza e compromete. Na perspectiva levinasiana, a modernidade é o momento histórico decisivo deste primado da liberdade:

Todo o pensamento filosófico e político dos tempos modernos tende a colocar o espírito humano num plano superior ao real, cava um abismo entre o homem e o mundo. Tornando impossível a aplicação das categorias do mundo físico à espiritualidade da razão, ele situa a base última do espírito fora do mundo brutal e da história implacável da existência concreta (LEVINAS, 1997, p. 12).

Eis o fundo idealista do pensamento europeu, ratificado pelo cristianismo, pelo liberalismo e mesmo pela fenomenologia transcendental. A luz da razão expulsa as sombras do irracional. A razão autônoma toma distância, liberta-se do predomínio da matéria, subtrai-se ao destino imposto pelas divindades míticas. Mas tal luminosidade é suficiente para a liberdade? O marxismo colocou em questão esta possibilidade, na medida em que insistiu sobre os condicionamentos históricos. Levinas, por sua vez, retoma a descrição fenomenológica da experiência corporal, experiência essa que ficou um tanto marginalizada no Ocidente, desde Platão. Com esta retomada, ele busca pensar a ambiguidade essencial da existência sensível.

Ora, o corpo não é acidental, não é um empecilho a ser ultrapassado. Pelo corpo, o Eu (Moi) encontra-se colado ou acorrentado a si mesmo. O hitlerismo, explica Levinas, se beneficiou desta constatação: há uma inevitável identidade entre o eu e o corpo, identidade esta que o próprio materialismo desconsiderou ao fazer do biológico um desafio objetivo para a razão. Para Levinas, o biológico é a marca de uma ambiguidade: a) é aquilo pelo que o eu está acorrentado e incapaz de sobrevoar o mundo e as contingências (Cf. LEVINAS, 1997, p. 19). Ao mesmo tempo, b) o corpo é o lugar em que se dá a articulação entre fatalidade e reparação, entre 
acorrentamento e começo livre, entre o tempo do destino e o tempo da novidade ou criação.

Dito de outro modo: o corpo nos coloca à mercê de um encantamento, pois a luta pela liberdade pode sempre resultar em servidão voluntária. Eis, com efeito, a experiência cruel da história do século XX. Nem mesmo Heidegger, que não é conhecido pela defesa da primazia do corpo próprio, escapou de ter uma vinculação a uma "filosofia" que se baseou justamente no encadeamento corporal do existente. Por quê? Comentando a leitura levinasiana do hitlerismo, Abensour afirmou:

Para Levinas, a fonte da barbárie nazista assentaria doravante - a despeito de toda contingência ou acidente - numa "possibilidade essencial do Mal elemental", relacionado "à ontologia do Ser preocupado em ser" (1997, p. 95).

O eu é um existente exposto à fatalidade, ao "encadeamento em si mesmo", mas é, curiosamente, graças a esta condição que ele pode ter consciência e vontade, bem como resistir à violência. Que é a consciência para Levinas? Nada mais que o ser voltado ao futuro, mas não como ser-para-a-morte, e sim como previsão da violência sempre iminente. Diferentemente de Heidegger, Levinas não compreende o tempo como antecipação do futuro. Relacionamo-nos ao porvir de outro modo: ser para o futuro é "tomar distância" em relação ao ser, mesmo que, inevitavelmente, estejamos presos a ele. O tempo é, assim, a consciência da violência possível, mas é igualmente um "poder de começar" e de iniciar. Nenhum destino poderia impedir este poder de falar e de romper. Na perspectiva levinasiana, em Husserl já se observa um subjetivo que se desprende da totalidade, isto é, um eu como origem, começo, princípio. (Cf. LEVINAS, 1994, p.119).

Mas, se em Husserl o corpo, mesmo perpassado por uma vulnerabilidade inevitável, é o órgão do querer e a condição da liberdade, Levinas procura mostrar que é no sofrimento que o poder de falar se torna consciência ética. Pelo corpo, somos acorrentados e incapazes de evasão. Mas esta fragilidade não deixa de ser, também, a marca de uma ambiguidade: o ser passivo se torna vontade e atividade na medida em que se distancia do presente. Como assim? É que o tempo é paciência, uma espécie de relação entre passividade e domínio. No sofrimento, o eu tem consciência de ser "coisa", mas sem deixar de ser sujeito ou de manter-se como tal (Cf. LEVINAS, 1978, p. 216). A violência não pode eliminar este poder de falar, intrínseco ao sujeito sensível. Nem tudo é inexorável ou definitivo, pois o eu é aquele que pode "sofrer por", "morrer por". Mesmo que o outro traga o sofrimento (pela violência), o egoísmo do eu já foi questionado. 
A vontade, por sua vez, se faz doação, resposta, fecundidade, um modo de "ser-para-além-damorte" e da história.

Bondade consiste em se colocar no ser de tal modo que Outrem importa, aí, mais do que eu mesmo. A bondade comporta, assim, a possibilidade para o eu, exposto à alienação de seus poderes pela morte, de não ser para a morte (LEVINAS, 1978, p. 225).

Resumamos o percorrido. Nada pode conter o mal Elemental, sempre iminente na história, no devir, no ser, na existência. Como explica Murakami: “A catástrofe real realiza aquilo que é sempre iminente no nível transcendental (...). Não há sociedade que escape aos problemas fatais" (2002, p. 28). Por outro lado, o eu que se mantém como sujeito, a despeito de sua condição de mortal e vulnerável, é aquele que se descobre como um "não poder esquivar-se", isto é, como um ponto, no universo, de onde o falar e o responder se tornam possíveis. A mortalidade se converte, então, em recursos da interioridade. Por esses recursos o tempo se torna fenômeno do "ainda não". De nossa parte, perguntamos: este poder responder, esta responsabilidade como condição ou in-condição do sujeito, não exige uma leitura positiva do conatus, isto é, do esforço do ser que persevera em seu ser? Não haveria uma face positiva do desejo de ser, inevitável em qualquer concepção ética que pretenda considerar a prioridade do outro sobre o mesmo? Ricoeur se pergunta, questionando Levinas, se não há um modo de valorizar a ontologia (e mesmo ontologias desativadas) sem se esquecer de articulá-la com a problemática levinasiana da alteridade. Afinal de contas, o eu que responde é sempre um eu capaz de iniciativa e de ação (Cf. RICOEUR, 1988, p. 180 e ss.). Ou ainda: é um eu capaz de compreender-se, não como capaz de se subtrair à história, mas sim de decifrar a si mesmo a partir de sua condição histórica.

\section{Condição histórica e responsabilidade pelo sentido}

É esta, com efeito, a proposta de Ricoeur, sobretudo em seu monumental estudo sobre a memória, a história e o esquecimento (Cf. RICOEUR, 2007). Na terceira parte da obra, dedicada à condição histórica, o filósofo se volta para o fundo ontológico do exercício da memória. Esta é entendida aristotelicamente como um "poder", uma "potência", uma "possibilidade", tal como ocorre no falar, no agir, no responder pelos atos próprios, etc.. Se, em Levinas, é a saída do ser que conta, ou seja, é decisivo descrever a suspensão do conatus sob a forma de subjetividade respondente, Ricoeur pensa as consequências práticas desse destacamento, dessa consciência moral. Ele opta, então, por uma resposta a Heidegger, para além da tese levinasiana segundo a 
qual a ética é a filosofia primeira, pois é fundamental saber não só que o ético introduz um sentido no ser (Levinas), mas também e, sobretudo, que é preciso realçar a nossa relação ao ser enquanto ser, pois, em última instância, somos seres históricos (Cf. RICOEUR, 2007, p. 359).

Como se sabe, o autor de Ser e Tempo privilegia, em nossa condição temporal, a antecipação, a relação ao futuro, a marcha em direção ao fim, numa palavra, Heidegger descreve o Dasein em termos de finitude. Eis por que "o ato filosófico, transido de angústia, procede do nada e se dispersa nas trevas" (RICOEUR, 2007, p. 362). Isso não mascara o entusiasmo em relação ao viver? "Não seria então necessário explicar os recursos da experiência do poder-ser aquém de sua captura pelo ser-para-a-morte?” (RICOEUR, 2007, p. 369). Recuperando o fundo husserliano da experiência originária enquanto corporeidade, Ricoeur se interroga sobre a questão da morte a partir do conceito de corpo próprio. Esta relação, em Heidegger, está ausente. A partir da existência encarnada, pode-se perguntar pelo desejo de ser, pelo esforço para existir, numa palavra, pode-se indagar se o fenômeno da morte não pode ser relacionado a esta situação carnal do sujeito (Cf. RICOEUR, 2007, p. 369). É toda uma compreensão de si a partir da relação entre morte e corpo próprio que se encontra em questão. Levinas, como vimos, privilegiou o lado violento e imprevisível desta condição. Tomou o conceito de corpo próprio para pensar a alteridade da morte como um "ainda não", um adiamento de um encontro fatal. Ricoeur, sem deixar de reconhecer a pujança da intuição de Levinas, investiga o lado mais positivo desta vulnerabilidade, ou exposição ao outro.

Qual a sabedoria que a mortalidade do corpo próprio ensina, para além do nada e do assassínio na noite? A condição mortal, explica Ricoeur, pode culminar com a sabedoria que consiste em aceitar a morte. Além do mais, a idéia de perda e de luto faz parte desta sabedoria possível. Ricoeur recupera contra Heidegger, e a favor de Levinas, a perda do outro como algo fundamental no fenômeno da morte. Quando o ser querido nos deixa, perdemo-nos a nós mesmos, e esta perda constitui, antes do luto, uma etapa do caminho da antecipação da morte própria (Cf. RICOEUR, 2007, p. 371). Na morte, não é algo exclusivamente meu que conta, pois o horizonte da morte do outro é fundamental na antecipação que eu mesmo realizo do fim. Mas, aqui, Ricoeur procura colocar a responsabilidade pelo sentido como desafio não explorado por Levinas. Também eu, no futuro, serei motivo de luto para outros. Este fato contribui para a aceitação de minha morte, gerando em mim um espírito de conciliação, uma chance de sabedoria ou serenidade estóica diante da finitude. De nossa parte, afirmamos e enfatizamos que o autor de 
Memória, História e Esquecimento é levinasiano, pelo menos em um ponto: os outros que não são meus próximos "exigem” algo que não vem de minha consciência solitária diante da morte, nem da relação amorosa que mantenho com meus entes queridos. É esta entrada do terceiro que nos coloca inevitavelmente na problemática da morte em história, bem como no dever de memória ou de justiça em relação a tantos seres humanos esquecidos (Cf. RICOEUR, 2007, p. 371).

Mas esta proximidade em relação ao pensamento levinasiano termina quando Ricoeur procura pensar a morte para além da fenomenologia da violência e do assassínio na noite. A ameaça da morte é, também, aquilo que nos aproxima como seres humanos, numa palavra, a morte anuncia o fim dos privilégios. Não só a crueldade pesa na morte, mas também o seu poder de equidade, uma vez que ela iguala nossos destinos. É nesse sentido que o discurso da história ou do historiador deixa de ser tomado como totalização ou absorção dos indivíduos para se tornar escrita capaz de fazer falar aqueles que já não têm mais voz: os mortos (Cf. RICOEUR, 2007, p. 379). Esse gesto de sepultamento oferece descanso definitivo aos que partiram, e assim fazendo, o historiador cria um espaço para os que ainda vivem, mas sem deixar de se aproximar do "tersido" dos que já morreram. Dito de outro modo, o trabalho do historiador realiza a repetição em sentido kierkegaardiano (Cf. KIERKEGAARD, 1990), isto é, re-pensa aquilo mesmo que fora vivido e pensado, resgatando o horizonte de expectativa dos seres humanos do passado. Mesmo que o acontecimento pretérito seja imutável, nem por isso o seu sentido está determinado de uma vez por todas (Cf. RICOEUR, 2007, p. 392). Historiar não é re-produzir, mas renovar seja a partir da narrativa e da interpretação, seja a partir do componente moral que este ato de contar encerra. Nas palavras de Ricoeur: “A história também compreende o passado como 'retorno' de possibilidades escondidas" (2007, p. 392).

É a repetição como força do possível que faz do discurso historiográfico não só um compromisso ético, mas também um poder ontológico capaz de lutar contra o esquecimento e as manipulações do esquecimento. Diante das experiências dolorosas e extremas, aquelas que tanto inquietaram Patocka e Levinas, o historiador e o filósofo não se deixam vencer pelo turbilhão do Elemental, pois a memória é, ao final das contas, o grande recurso, capaz até mesmo de oferecer, para o presente, o esquecimento justo, ou seja, o esquecimento que não ficou do lado da omissão, da má-fé, do medo e do próprio mal. O grande desafio é, assim, dizer o mal de modo apaziguado e sem cólera (Cf. RICOEUR, 2007, p. 462). Os crimes históricos que marcaram o século XX nos ethic@-Florianópolis, v. 11, n. 1, p.125-139. Jun. 2012. 
colocam no confronto inevitável com o injustificável e com o inaceitável, pois como defender os danos causados a outrem por meio do assassinato, da morte, do mal? Como explicar-se diante da ruptura do vínculo humano, a maldade íntima que um ser humano pode ocasionar ao outro homem, como gosta de dizer Levinas? É assim que Ricoeur realiza uma descida às profundezas da experiência da falta, não para defender o caráter trágico ou existencial da culpa, nem tampouco para descrever o sem-sentido que a dor gratuita infligida a outrem anuncia, mas sim para propor que, a despeito do desastre inapagável, o perdão, anunciado de uma "altura" que a escrita levinasiana explorou tão bem, é possível. Seria o perdão uma defesa imoral da absolvição gratuita e covarde?

Se não é na condição de sujeitos responsáveis ou marcados pelo mal que podemos perdoar, é porque o perdão é algo excepcional e extraordinário, uma oferta vinda de uma generosidade que nem mesmo a dor e o mal podem vencer. Não é um sujeito ou uma ipseidade que podem perdoar, simplesmente porque "há perdão como há a alegria, como há a sabedoria, a loucura, o amor" (RICOEUR, 2007, p. 473). Na fenomenologia de Levinas, o perdão é a obra mesma do tempo, vale dizer, é o triunfo do tempo da fecundidade sobre o envelhecimento e a morte. O perdão é uma inversão da ordem natural das coisas, ou seja, é a reversibilidade do tempo. Como assim? É que, na perspectiva levinasiana, o perdão repete o passado purificando-o. Graças ao perdão, os instantes não se conectam uns aos outros indiferenciadamente. Há, então, novidade, irrupção do não-idêntico. "O tempo, afirma Levinas, é o não-definitivo do definitivo, alteridade sempre re-começante do realizado - o 'sempre' do recomeço" (1978, p. 260). Não se trata de um gesto moral de um sujeito, nem da relação que o Dasein mantém com a morte, mas, sim, ruptura, descontinuidade, ressurgimento. Nas palavras e Ricoeur: "O perdão interrompe o fluxo comum da temporalidade histórica" (2007, p. 475). No entanto, nem Ricoeur nem Levinas se esqueceram de sustentar que, sem o esforço para que a justiça seja feita, a graça do perdão seria uma imoralidade.

O compromisso ético com a memória do Holocausto e dos acontecimentos traumáticos do século passado aproxima Ricoeur de Levinas. Esta aproximação não anula as diferenças, mas propicia um diálogo crítico que pode se realizar em várias frentes e, a nosso ver, de modo inesgotável. Tomemos apenas um exemplo para concluir. Em Ricoeur, o tema da memória se impõe não apenas em sentido epistemológico, fenomenológico ou hermenêutico, mas, sobretudo, ético. A impressão traumática que essas ocorrências desastrosas deixaram nos corpos e nos 
corações humanos não pode ser esquecida. Em Levinas, a história se estrutura a partir de um “para além da lembrança”. É como se toda a humanidade estivesse incluída numa história nãorememorável: aquela das provações da escravidão e da libertação da escravidão. A memória seria, então, a "compaixão por todos os dominados e todos os danados da terra, bem como o faro especial para esta danação, faro este que os próprios danados são levados a esquecer". (LEVINAS, 1988, p. 91). Passagem do não-sentido ao sentido, eis a possibilidade do humano que estrutura a própria história. E quanto a Ricoeur? Ele complementaria, dizendo: passado "para além da lembrança", sim, mas que por isso mesmo pede para ser dito, narrado, compreendido. Desafio de sentido que se traduz por escrita comprometida com o rosto dos que existiram no passado, isto é, com aqueles que agiram e sofreram, fazendo promessas que não puderam cumprir. O cumprimento dessas promessas não está nas mãos do historiador, mas na dos seres humanos que vivem no presente, isto é, em nossas mãos. Mais do que escrever a história, é fundamental fazer a história. Por conseguinte, se for verdade que a guerra é sempre iminente em todo processo temporal (Levinas), também é verdade que o desejo de ser sempre pode ressurgir por trás das provações humanas do inumano (Ricoeur). A esse respeito, o diálogo entre os dois filósofos estará sempre em aberto. 
FABRI, M. Levinas, Ricoeur e os imprevistos da história.

\section{Notas}

1 e-mail: fabri.ufsm@gmail.com

ethic@-Florianópolis, v. 11, n. 1, p. 125 - 139. Jun. 2012. 


\section{Referências Bibliográficas}

ABENSOUR, M. Le Mal Elemental. In: LEVINAS, E.- Quelques réflexions sur la philosophie de l'hitlerisme, Paris: Payot/Rivages, 1997, pp.. 27-108.

HEIDEGGER, M. Ser e Tempo. Trad. Márcia de Sá Cavalcanti, Petrópolis: Vozes, 2002 (1 1 Edição).

HUSSERL, E. La crise des sciences européennes et la phénoménologie transcendentale. Trad. Gérard Granel, Paris: Gallimard, 1976.

HUSSERL, E. Idées diréctrices pour une phénoménologie et une philosophie phénoménologiques pures (Livre second), Recherches phénoménologiques pour la constitution. Trad. Eliane Escoubas, Paris, PUF, 1982.

HUSSERL, E. Idéias para uma fenomenologia pura e para uma filosofia fenomenológica. Trad. Márcio Suzuki, Aparecida (SP): Artes e letras, 2006.

HUSSERL, E. Leçons sur l'éthique et la théorie de la valeur (1908-1914). Trad. Philippe Ducat, Patrick Lang e Carlos Lobo, Paris: PUF, 2009.

KIERKEGAARD, S. La reprise. Trad. Nelly Viallaneix, Paris : Garnier-Flammarion, 1990. LEVINAS, E. - Totalité et Infini, La Haye: Martinus Nijhoff, 1978.

LEVINAS, Emmanuel. Du sacré au saint: cinq nouvelles lectures talmudiques, Paris: Minuit, 1977.

LEVINAS, Emmanuel. À l'heure des nations, Paris: Minuit, 1988.

LEVINAS, E. En découvrant l'existence avec Husserl et Heidegger, Paris: Vrin, 1994.

LEVINAS, E. Quelques réflexions sur la philosophie de l'hitlerisme, Paris: Payot/Rivages, 1997.

MURAKAMI, Y. Lévinas phénoménologue, Grenoble: Jérôme Millon, 2002.

PATOCKA, J. Essais hérétiques sur la philosophie de l'histoire. Trad. Erika Abrams, Lagrasse: Verdier, 1999.

RICOEUR, P. J'attends la Rennaissance (Entretient avec Paul Ricoeur). In: A quoi pensent les philosophes, Paris: Autrement, 1988, n. 102 (novembre), pp. 175-183.

RICOEUR, P. Prefácio a PATOCKA, J. - Essais hérétiques sur la philosophie de l'histoire. Trad. Erika Abrams, Lagrasse: Verdier, 1999.

RICOEUR, P. A memória, a história, o esquecimento. Trad. Alain François, Campinas: Unicamp. 2007. 